\title{
Influence of running-in on surface characteristics of efficiency tested ground gears
}

\author{
D. Mallipeddi $^{\text {a, *, }}$ M. Norell ${ }^{\text {a }}$, M. Sosa ${ }^{\text {b }}$, L. Nyborg ${ }^{\text {a }}$ \\ ${ }^{a}$ Industrial and Materials Science, Chalmers University of Technology, SE-41296 Gothenburg, Sweden \\ ${ }^{\mathrm{b}}$ Machine Design, KTH Royal Institute of Technology, SE-100 44 Stockholm, Sweden
}

\section{A R T I C L E I N F O}

\section{Keywords:}

Gears

Running-in

Efficiency test

Residual stresses

Micropitting

Tribofilm

\begin{abstract}
A B S T R A C T
The effect of running-in load $(0.9$ or $1.7 \mathrm{GPa})$ on surface characteristics of ground spur gears, and on their development during subsequent efficiency testing (FZG rig), is examined. The effect was confined to less than $10 \mu \mathrm{m}$ depth. Micropitting was associated with surface asperities and their plastic deformation; higher running-in load gave more micropitting, also after identical efficiency tests. Running-in increased unequal compressive residual stresses in both profile and axial directions, while after efficiency testing they approached equal levels. Deformation induced martensite is considered to form during running-in only at high load, still the amount after efficiency testing increased with running-in load. Higher surface content of phosphorous from extreme pressure additive (EP) occurred only after efficiency test following running-in at high load.
\end{abstract}

\section{Introduction}

Running-in is known to smoothen surface asperities and enhance gear efficiency. However, it will also affect the surface chemistry, residual stresses and microstructure near the surface, factors that will influence the efficiency and durability of the gear.

Gears are renowned for their high transmission efficiency in vehicle applications. A recent study on heavy-duty vehicles indicated that $5.1 \%$ of the fuel energy is accounted to overcome transmission friction, of which gears alone consume 55\% [1]. Hence, increasing gear efficiency has become an active field of research. Apart from design parameters, the influence of surface topography on gear efficiency is also studied. For example, Andersson, Petry-Johnsson and Britton [2-4] have found that super-finished gears has significantly improved efficiency compared to ground gears.

Irrespective of manufacturing method, surface asperities will be further smoothened through running-in and this will lead to better conformity between mating gears. Andersson [5] found that the surface roughness of both hobbed and shaved gears was altered by the running-in process. However, the decrease in surface roughness was higher for hobbed gears with higher initial surface roughness. Plastic deformation and wear are the two important mechanisms that are responsible for creating changes in surface topography during running-in, especially for rolling-sliding contact [6]. As a consequence of modification in topography, the friction pair will tend to reach steady state condition with respect to contact pressure, surface roughness, surface microstructure and the establishment of effective lubricating film at their interface [7].

Running-in of gears performed under controlled conditions has major impact on durability and mesh efficiency. The effectiveness of running-in depends on factors such as load, speed, physicomechanical properties of material and lubrication medium [8]. Sjöberg [9] showed that higher running-in load yields higher gear mesh efficiency and has greater effect on surface roughness parameters compared to a lower running-in load. Cavatorta [10] and Kragelsky [8] also reported that increased load significantly increased the proportions of deformed asperities. However, the initial wear of gear flank was shown to accelerate with increasing speed and contact pressure [5].

In general, gear pair in operation are in cyclic rolling-sliding contact. Depending on the load magnitude, surface roughness and contact kinematics, the tooth flank may experience failures in the form of pitting or spalling [11]. Ariura et al. [12] reported that tooth surfaces are grey stained prior to pitting and claimed the reason being the degradation of the tooth profile. Micropitting, or grey staining, can be explained as fatigue failure that typically starts with the generation of surface cracks that propagate at a shallow inclined angle into the surface [13]. This usually occurs during the first $10^{5}-10^{6}$ stress cycles, but with unfavourable conditions or having a lubricant with too low load carrying capacity, micropitting can readily begin already after short running time [14] even at moderate loads. Oila et al. [15] concluded, in a study conducted on factors influencing micropitting in rolling-sliding contact, that

\footnotetext{
* Corresponding author.

E-mail address: mdinesh@chalmers.se (D. Mallipeddi).
} 
contact load is a prime factor for initiation, whereas speed and slide/roll ratio related more to propagation.

Oila [16,17] investigated micropitting in gears associated with microstructural changes. He observed martensite decay i.e. formation of dark etching regions (DER) and white etching bands (WEB) beneath the plastically deformed regions (PDR) of asperities and proposed boundaries of PDR as preferential sites for microcrack initiation and propagation. Hoeprich [18] proposed that DER in contact fatigued gears was due to plastic deformation and dislocation accumulation rather than microstructure/phase transformation. Bush [19] in his work on ball bearings showed that no structural alterations occur below a threshold load. Marked changes in residual stresses above this threshold was also reported, though the measurements started $25 \mu \mathrm{m}$ below the surface. In addition, residual stress induced by surface treatment can also influence contact fatigue of gears [20].

Lubrication oil with extreme pressure additives (EP) plays a prominent role in the load carrying capacity of gears. Depending on the evolution of surface topography with respect to the operating conditions, the lubricant can protect gear surfaces by separating the gear pair involving the formation a reaction layer. Krantz [21] studied the effect of specific film thickness (influenced by surface topography) on gear pitting life. He found that the surface fatigue life was approximately 8 times longer for gears operating with specific film thickness above 2 compared to the ones operating below 0.8 . Furthermore, additives can form low shear strength tribofilms over gear surfaces by adsorption and ultimately chemical surface reactions. Formation of such films prevents the asperity contacts and reduce shearing of the metal, thereby minimising friction. A study conducted on roller bearings showed that a running-in procedure with higher rotational speed or lower load promoted tribofilm formation [22]. However, no such study has been found for gears, despite the typically higher surface roughness and sliding ratio.

The main objective of this research initiative is to depict the evolution of surface characteristics of ground gears for different running-in loads. The work also addresses how these characteristics further develop and may influence gear behaviour during the initial use, here represented by efficiency testing. Examined characteristics include topography with deformation of asperities and formation of micropits, residual stresses, microstructural changes as well as surface chemistry related to the formation of tribofilms. The very same gears have previously been tested in a study in the influence of running-in on efficiency [9] and the results will be compared.

\section{Materials and experimental procedure}

\subsection{Materials, manufacturing and gears}

Spur gears made of alloy $16 \mathrm{MnCr} 5$ were tested. The gears had been case- hardened, tempered and finally hard finished by generating grinding. The case depth was about $1 \mathrm{~mm}$ with a surface carbon content of about $0.8 \mathrm{wt}-\%$. The heat treatment and grinding parameters are presented in Table 1.

The geometrical data of modified FZG C-Pt type spur gears used in this study is presented in Table 2 . The inclusion of tip relief made these gears different from standard FZG C-Pt gears [23].

Table 1

Processing parameters.

\begin{tabular}{ll}
\hline Carburizing & $930^{\circ} \mathrm{C}, 8 \mathrm{~h}$ \\
Diffusion & $850{ }^{\circ} \mathrm{C}, 1 \mathrm{~h}$ \\
Quenching & $135^{\circ} \mathrm{C}$ \\
Tempering & $180^{\circ} \mathrm{C}, 3 \mathrm{~h}$ \\
Grind Machine & $\mathrm{LCS} 300$ \\
Grinding Worm & Corundum \\
Nr of passes & 3 \\
Cutting speed & $59 \mathrm{~m} / \mathrm{s}$ \\
Feed Rate & $0.19 \mathrm{~mm} / \mathrm{tr}$ \\
Nominal cutting depth & $1 \mathrm{~mm}$ \\
\hline
\end{tabular}

Table 2

Geometrical parameters of gears.

\begin{tabular}{llcc}
\hline Parameter & Gear & & Pinion \\
\hline Number of teeth & 24 & 16 \\
Pressure angle $\left(^{\circ}\right)$ & & 20 & \\
Center Distance $(\mathrm{mm})$ & & 91.5 & \\
Module $(\mathrm{mm})$ & & 4.5 & \\
Face width $(\mathrm{mm})$ & 109.8 & 14 & \\
Pitch Diameter $(\mathrm{mm})$ & 118.4 & & 83.2 \\
Tip Diameter $(\mathrm{mm})$ & 115.9 & & 80.3 \\
Tip relief starting Diameter $(\mathrm{mm})$ & & 20 & \\
Tip relief $(\mu \mathrm{m})$ & 0.171 & & 0.182 \\
Profile shift & & &
\end{tabular}

\subsection{Test rig details}

An FZG back-to-back gear test rig with efficiency set-up was used for performing running-in and efficiency tests (Fig. 1). Gears with the same geometry were used in both the slave and test gearboxes. Two shafts are used to connect slave gears and test gears; one of the shafts is separated into two parts with a load clutch in between. Torque is applied to the system by twisting the clutch with the help of lever and dead weights. All analyses have been done on the driven gear wheel.

\subsection{Running-in and efficiency testing}

The running-in procedure consisted of an inside power loop torque of 94 or $302 \mathrm{Nm}$ (referred to as load stage 5 (LS5) and load stage 9 (LS9) according to FZG manual guide [24]) for the pinion, at $0.5 \mathrm{~m} / \mathrm{s}$ pitch velocity (87 rpm for the wheel), dipped in a fully synthetic poly-alpha olefin (PAO) lubricant controlled at $90{ }^{\circ} \mathrm{C}$ for $4 \mathrm{~h}$. This amounts to 20880 revolutions for the wheel. The torques correspond to Hertzian pressures at the pitch of 0.9 and $1.7 \mathrm{GPa}$, respectively.

The efficiency test following running-in consisted of 32 conditions, i.e. four loads and eight speeds. The test started with an inside power loop torque of $0 \mathrm{Nm}$, sweeping through speeds $0.5,1,2,3.2,8.3,10,15$ and $20 \mathrm{~m} / \mathrm{s}$ pitch velocity for $5 \mathrm{~min}$ at each speed, using the same lubricant and temperature control as in the running-in procedure. Once the highest speed was tested, the same speeds were swept for 94,181 and $302 \mathrm{Nm}$. The temperature was maintained at $90{ }^{\circ} \mathrm{C}$, but for one test condition it was $120^{\circ} \mathrm{C}$.

Andersson et al. [2] have calculated the film thickness during running-in and the different speed and load combinations which these ground gears are subject to in this study. They reported a lambda ratio (film thickness over composite rms roughness) of approximately 0.1 for both RI5 (LS5) and RI9 (LS9) tests. The running-in procedure is hence in the boundary condition. During the efficiency testing lambda ranges from 0.1 to 1.5 for the different speed and load combinations [2]. The efficiency procedure is run therefore through boundary and mixed lubrication for the tested ground gears.

The detailed test matrix with the designation of individual tests is

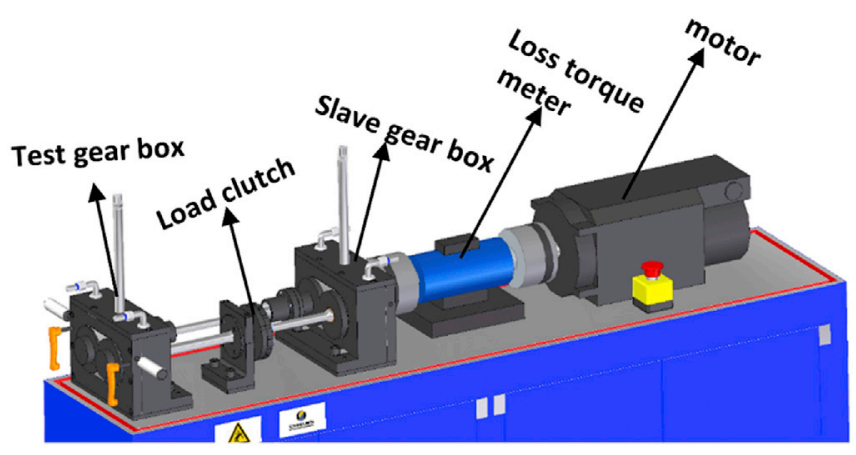

Fig. 1. Schematic of FZG back-to-back gear test rig. 
presented in Table 3. The test designations RI5 and RI9 indicate runningin tests at corresponding load stages, whereas, RI5+E and RI9+E indicates running-in tests followed by efficiency testing. For one specific test condition RI5+E-120, the temperature was $120{ }^{\circ} \mathrm{C}$ during the efficiency test.

Additionally, a static immersion test (SIT) was performed to investigate additive adsorption on gear tooth surface. In this test, an as-ground gear tooth was dipped in lubricant oil at $90^{\circ} \mathrm{C}$ for $4 \mathrm{hrs}$ (similar to running-in test time and temperature).

\section{Characterization methods}

\subsection{Surface topography, profilometer}

Two different profilometers were used to characterize the surface topography of the gear tooth. The first was a Form Talysurf PGI 800 (Taylor Hobson) used to perform 3D measurements before testing in order to understand the overall topography of the tooth. The second was a Form Talysurf $50 \mathrm{~mm}$ Intra 2. The latter was used for measuring the surface topography in situ initially, after running-in and after efficiency testing. Both profilometers used $2 \mu \mathrm{m}$ styli tips. More information on the in situ method used can be found in Ref. [25].

\subsection{Microscopy}

Surface topography examinations and microstructural analyses of gear teeth were performed by using scanning electron microscopy (SEM). The instrument was LEO Gemini 1550 equipped with field emission gun. The imaging was done at an acceleration voltage of $5 \mathrm{kV}$. The microstructure was also examined by optical microscopy.

\subsection{X-ray diffraction}

Residual stress measurements were performed using a XSTRESS 3000 G2R diffractometer with a $\mathrm{Cr}$-K $\alpha$ X-ray source and the lattice deformations for $\{211\} \alpha-F e$ peak was measured. Standard $\sin ^{2}(\psi)$ technique [26] with five equi-sin ${ }^{2}(\psi)$ tilts from $-45 /+45$ was used for determining the stress values. Measuring residual stress in gears is very complex because of the involute profile and the risk for interference of incident and diffracted beams with the adjacent teeth. To avoid these complexities, gear teeth were cut out from gear wheel. The stresses were measured in both profile and axial direction of the gear tooth. For gears, pure rolling occurs along the pitch-line, positive sliding along the addendum and negative sliding along the dedendum regions [27]. Therefore, measurements were done at three different positions in profile direction, all close to the centre of face width in axial direction. The positions for the measurements along with their designations are illustrated in Fig. 2. To measure the subsurface stresses, layer of material was removed stepwise by electrochemical etching using a $3 \mathrm{M} \mathrm{NaCl}$ solution as electrolyte. The etched area was $3.5 \mathrm{~mm}$ in diameter and a collimator with diameter $1.5 \mathrm{~mm}$ was used for irradiating X-rays. After every step, a stylus profilometer was used for measuring the depth, shape, and roughness of the hole.

The volume fraction of retained austenite was also measured using XSTRESS 3000 G2R. The exposure time was set to $30 \mathrm{~s}$ with a $1.5 \mathrm{~mm}$

Table 3

Detailed test matrix with designations.

\begin{tabular}{|c|c|c|c|c|}
\hline \multirow[t]{2}{*}{ Test Designation } & \multicolumn{2}{|c|}{ Running-in } & \multicolumn{2}{|c|}{ Efficiency } \\
\hline & LS5 & LS9 & $90^{\circ} \mathrm{C}$ & $120^{\circ} \mathrm{C}$ \\
\hline RI5 & $\mathrm{x}$ & & & \\
\hline RI9 & & $\mathrm{x}$ & & \\
\hline $\mathrm{RI} 5+\mathrm{E}$ & $\mathrm{x}$ & & $\mathrm{x}$ & \\
\hline RI5 + E-120 & $\mathrm{x}$ & & & $\mathrm{x}$ \\
\hline $\mathrm{RI9}+\mathrm{E}$ & & $\mathrm{x}$ & $\mathrm{x}$ & \\
\hline
\end{tabular}

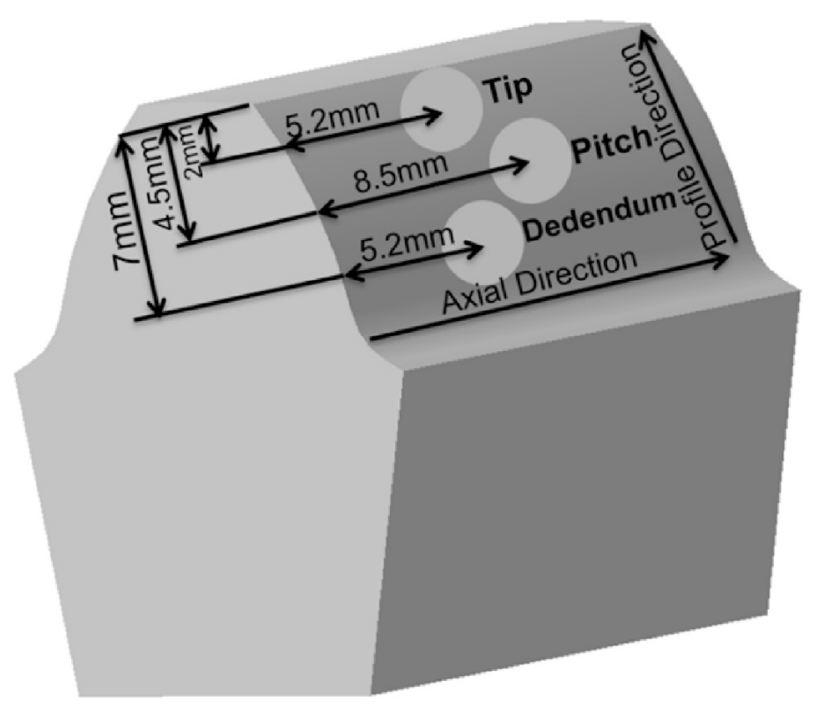

Fig. 2. Locations on gear tooth for residual stress measurements.

collimator, an inclination of $+45^{\circ}$ and scanning $\pm 85^{\circ}$ with 15 steps. The peaks of the diffraction planes $\{200\} \gamma,\{220\} \gamma$ and $\{200\}_{\alpha},\{211\}_{\alpha}$ were used for the analysis. For depth analysis the same etching procedure as for residual stress measurements were employed. The retained austenite was only characterized at dedendum, at the same position as the stresses.

\subsection{Surface chemistry}

Surface chemical analysis and compositional depth profiling on the gears tested for different conditions were done by X-ray photoelectron spectroscopy (XPS) using a PHI 5500 spectrometer, operated with monochromatic $\mathrm{Al} \mathrm{K \alpha}(1486.6 \mathrm{eV})$ source and the aperture set to give an analysis area $\sim 0.8 \mathrm{~mm}$ in diameter. For measurements, tooth from the gear wheel was cut out, cleaned in ultrasonic bath with first xylene and then ethanol for 5 min each. Argon ion etching was used for depth profiling with etch rate as calibrated on $\mathrm{Ta}_{2} \mathrm{O}_{5}$. Both survey spectra and high resolution spectra were acquired at each depth. Measurements were executed at tip, pitch and dedendum surfaces. Stainless steel masks with involute shape were used to reproducibly position the analysis areas and protect the remaining surface from ion etching. To maintain the take off angle at $45^{\circ}$, with the sample mounting used, the stage was tilted $0^{\circ}, 11^{\circ}$ and $15^{\circ}$ for dedendum, pitch and tip respectively.

\section{Results}

\subsection{Gear surface topography}

\subsubsection{Surface topography of as-ground gear tooth}

The grinding lay of an as-ground gear flank is shown in Fig. 3. It consist of adjacent peaks and valleys with irregular surface asperities along the axial direction. These surface micro-features are considered to play a prominent role in contact fatigue.

The 3D surface topography measured with the profilometer can be seen in Fig. 4. The same distinct ridges from grinding as found in the SEM images is seen in these measurements.

\subsubsection{Surface topography after running-in and efficiency testing}

To demonstrate areas affected by micropitting, the macro-photo of gear tooth (driven gear) after the efficiency test RI9+E is shown in Fig. 5. Micropitting is extensive between the white lines at dedendum, close to end of active profile (EAP).

To compare the evolution of surface topography, the dedendum gear surfaces along the EAP for different test conditions are shown in Fig. 6. The stitched SEM micrographs reveal that micropitting occurred readily 


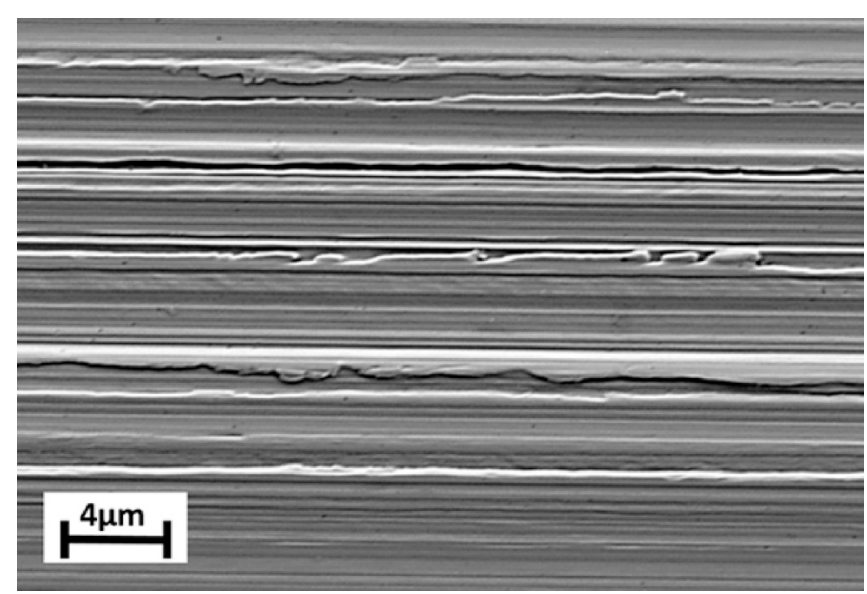

Fig. 3. Surface topography of an as-ground gear tooth, higher magnification SEM imaging.

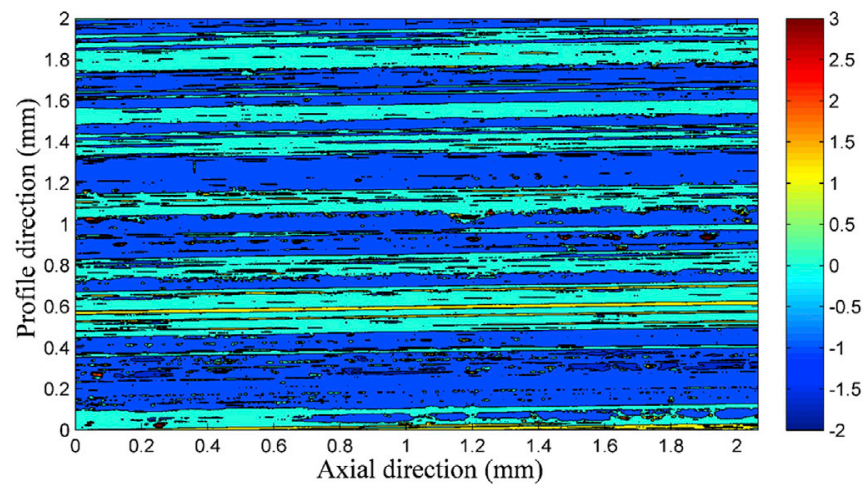

Fig. 4. Surface topography (3D) of an as-ground gear tooth as measured with profilometer.

after running-in, but the amount of micropits was higher for RI9 compared to RI5. It can also be observed that the degree of micropitting increased after efficiency testing. For test condition RI9+E coalescing micropits had formed close to one another, whereas for RI5+E a multitude of micropits some distance apart can be seen. The efficiency testing at $120^{\circ} \mathrm{C}$ resulted in a very smooth surface with less micropits compared to testing at $90{ }^{\circ} \mathrm{C}$. The morphology of micropits at dedendum is

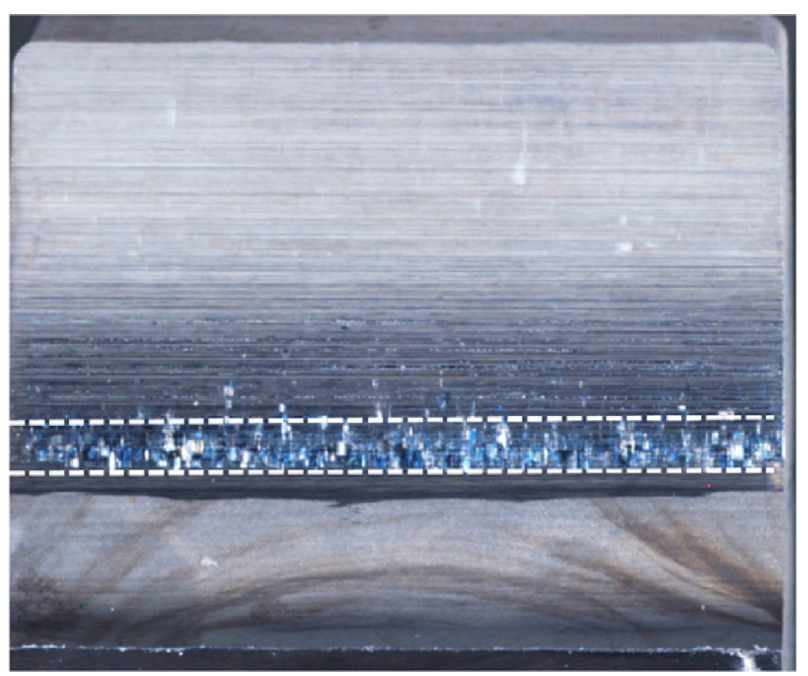

Fig. 5. Macro photo of gear tooth after RI9+E. illustrated in Fig. 7. It is seen from the micrographs that the growth of micropits was opposite to the sliding direction, in accordance with ref. [28]. Furthermore, the high asperity peaks appears to be plastically deformed and cover adjacent valleys.

Fig. 8 shows the surface topography at tip surface with one micrograph for each condition. Different deformation patterns can be seen, but at this magnification, the area proportions are not representative. It is interesting to see that after RI5 the topography still resembles the asground condition indicating limited plastic deformation. Micropits appeared at the tip surface for RI9. After efficiency test RI5+E the grinding lay cannot be seen in some areas where plastic flow in profile direction have occurred, without any micropitting. A similar appearance though with a smoother surface is visible after RI5+E-120, while RI9+E has more micropits than any other test condition also at the tip.

The SEM micrographs close to the pitch line revealed some scattered micropits for all test conditions except for RI5. Otherwise, plastic deformation was seen prominently. As an example, a SEM micrograph from RI5+E is shown in Fig. 9. It can be observed that asperities are plastically deformed downwards in the direction of sliding and appears to cover valleys in the grinding lay. Thus, both the peaks and valleys are smoothened, but the material is strongly deformed.

\subsubsection{Surface roughness}

Surface roughness parameters for the surfaces shown in the SEM micrographs above are presented in Table 4. These parameters were measured in-situ with the Form Talysurf Intra $50 \mathrm{~mm}$ on as-ground gears (initially), after running-in, and after efficiency testing. The in situ method allows the measurement of surface parameters without disturbing the overall assembly of the gearbox. Overall, a smoother surface was measured for RI9, when compared to RI5, which is in line with what is presented in Figs. 6 and 8.

The data, however, is not as conclusive when analysing the results after efficiency testing. After efficiency testing at $90^{\circ} \mathrm{C}$, the surface shows further smoothening, especially when comparing the Rpk values. Instead, for RI5+E-120 an overall rougher surface is shown in the roughness parameters, which apparently contradicts what is seen looking at the asperities in Figs. 6 and 8. This discrepancy can be attributed to local roughening (damage) that occurs after efficiency testing along part of the $5 \mathrm{~mm}$ long profile, while other parts are smoothened [9]. Fig. 10 shows a shorter surface segment and indicates how individual asperities have been worn off after running-in.

\subsection{Residual stresses}

The residual stress profiles measured in both profile and axial direction of an as-ground tooth are shown in Fig. 11. It is evident from the graph that the stresses in both directions were compressive. However, the surface stresses induced by grinding in profile direction were more than twice those in axial direction. Below the surface, i.e. from about $5 \mu \mathrm{m}$, the stress levels are quite similar in both directions. After running-in, the compressive residual stresses had increased in both directions but only in a layer very close to the surface. Fig. 12 shows that RI5 gave higher surface stresses in profile direction than RI9, while the opposite occurred in axial direction. Notably, the dedendum surface had higher stresses in both directions compared to tip and pitch. The residual stresses changed also after efficiency testing but again the change was confined to the outermost $5 \mu \mathrm{m}$ (not shown).

Actually, the distribution of the residual stresses at the surface have been mapped over the gear flank on these gears, see Ref. [29]. Fig. 13 summarizes the stresses at dedendum in three points in axial direction. It illustrates how the stresses increased in both axial and profile direction after running-in (arrows on left side). After efficiency testing, for both RI5 and RI9, the stresses decreased in profile direction and increased in axial direction towards a rather uniform stress level of about $450 \mathrm{MPa}$. 

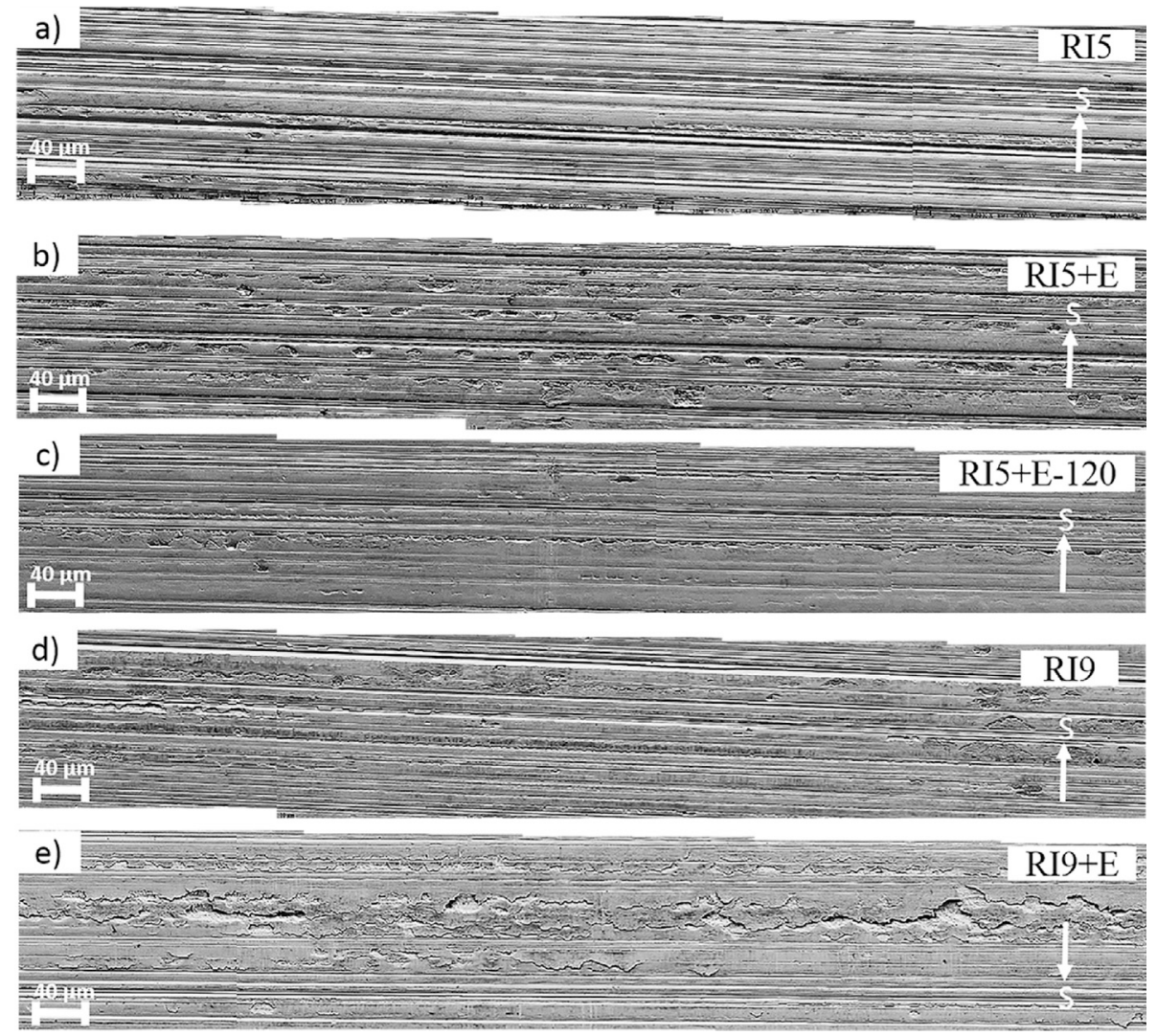

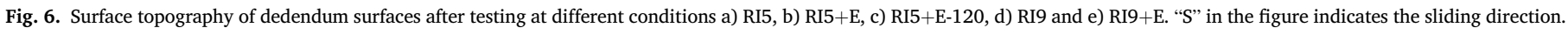
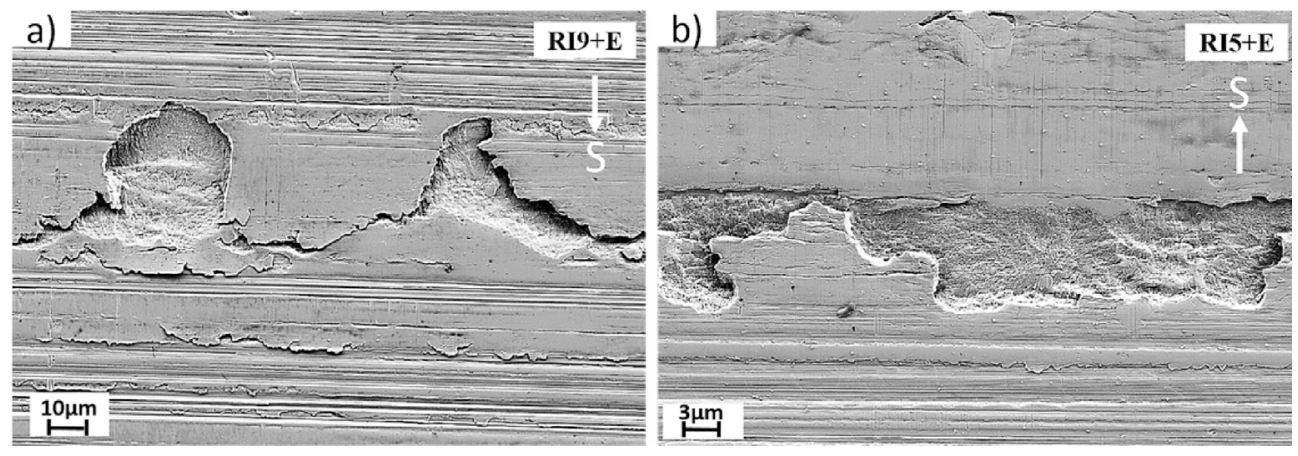

Fig. 7. SEM micrographs showing micropitting at dedendum after efficiency testing a) RI9+E and b) RI5+E. "S" indicates the sliding direction.

\subsection{Microstructure}

The microstructure of the case hardened layer consists of plate martensite and about 20\% retained austenite. The depth profiles of retained austenite measurements at dedendum surface for as-ground and efficiency test conditions are shown in Fig. 14. It is evident from the graph that no transformation of retained austenite can be quantified by means of XRD even after efficiency testing.

For every test condition except RI5, the metallographic investigations revealed the presence of a distinct structure near the teeth surface that was not present on as ground gears. Fig. 15 shows microstructures near the surface for RI9 and RI9+E, where the distinct features are indicated with dotted lines. Their morphology consists of parallel bands, sometimes intersecting, with sharper contrast and edges than in the plate martensite. They appear very close to the surface and extended to a maximum depth of about $7 \mu \mathrm{m}$. Though it is difficult to quantify the small amounts, more of this structure was formed after the efficiency tests and in particular for RI9+E. The morphology resembles that of deformation induced martensite in stainless steel [30]. Formation of deformation induced martensite from retained austenite has been observed after fatigue testing of case carburized gears [31]. The features observed here are also considered as deformation induced martensite as further discussed below.

Etched cross sections of tested gears examined under light optical microscope revealed no features like dark etching regions or white etching bands. However, surface features where no martensite plates can be seen were observed at high magnification using SEM. These features were observed for all efficiency test conditions, examples are indicated with white dots in Fig. 16. They were observed randomly along the profile of gear tooth but slightly more prominent at dedendum. These features are typically around $4 \mu \mathrm{m}$ in width. It has been suggested that the accumulation of plastic deformation is a reason for this type of structural feature, referred to as plastic deformation region (PDR) [17].

Dedendum cross sections of gear teeth cut along the profile direction 

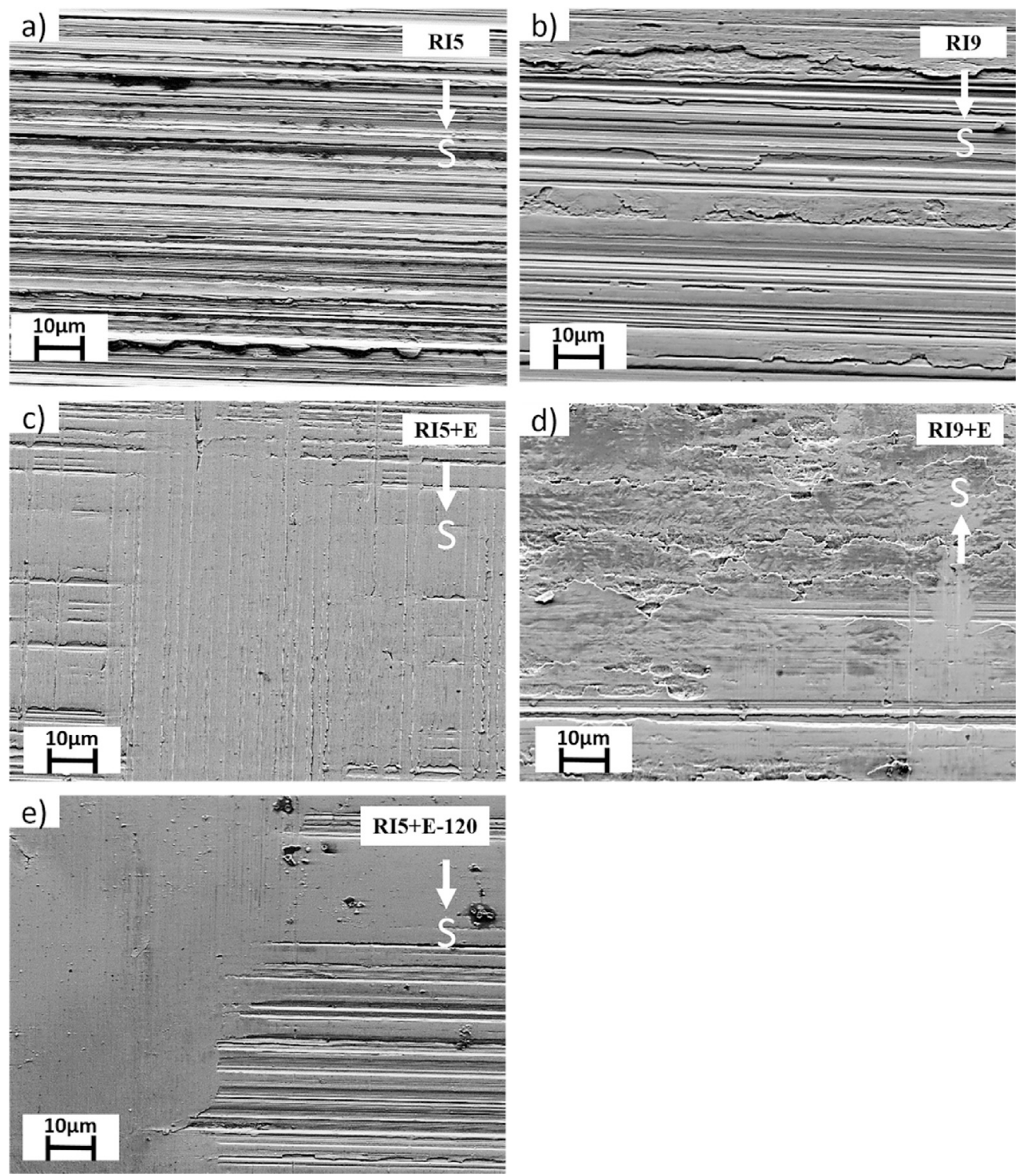

Fig. 8. Surface topography of tip surfaces after testing at different conditions a) RI5, b) RI9, c) RI5+E, d) RI9+E and e) RI5+E-120. "S" indicates the sliding direction.

for different test conditions are shown in Fig. 17. The negative sliding in the dedendum caused the surface below the asperities to deform and flow in the direction of sliding. Wedges that may cause stress concentrations were also seen and sometimes connected with small cracks, most clearly

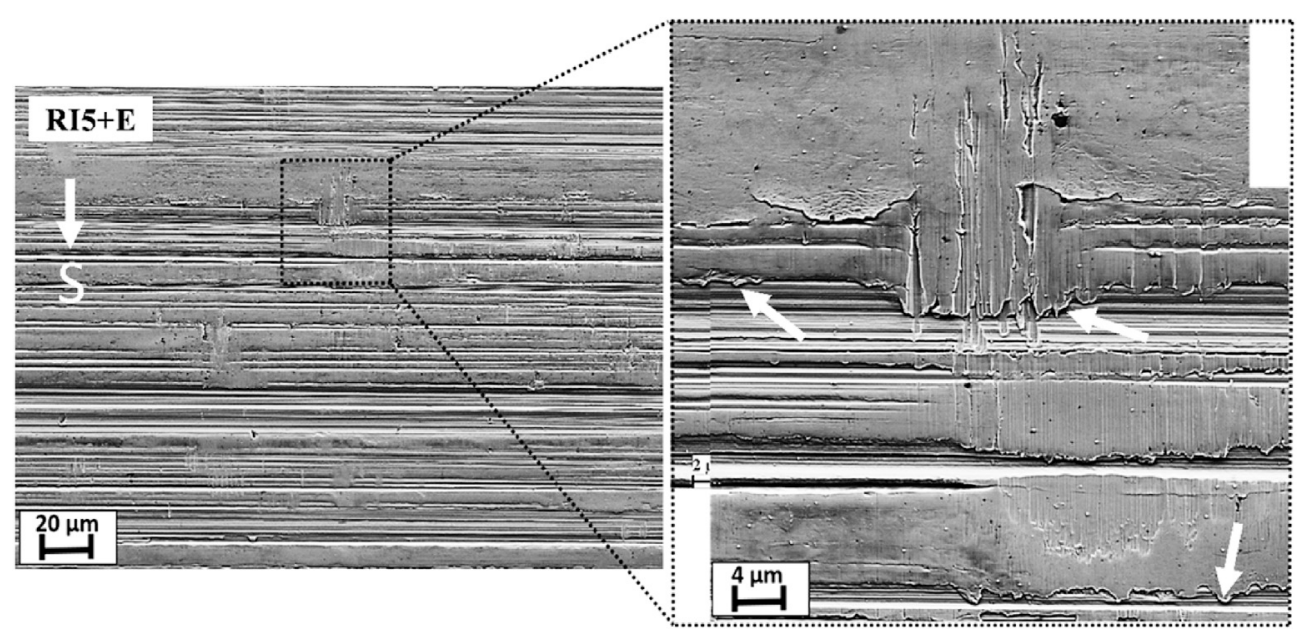

Fig. 9. SEM micrographs showing plastic deformation at pitch after efficiency testing RI5+E. "S" indicates the sliding direction. 
Table 4

Surface geometrical parameters of tested gears.

\begin{tabular}{|c|c|c|c|c|c|c|c|c|c|}
\hline & \multicolumn{2}{|l|}{ Initial } & \multicolumn{2}{|l|}{ RI9 } & \multicolumn{2}{|l|}{ RI5 } & \multirow{2}{*}{$\frac{\mathrm{RI} 5+\mathrm{E}}{\text { Mean }}$} & \multirow{2}{*}{$\frac{\mathrm{RI} 5+\mathrm{E} 120}{\text { Mean }}$} & \multirow{2}{*}{$\frac{\mathrm{RI9}+\mathrm{E}}{\text { Mean }}$} \\
\hline & Mean & STD & Mean & STD & Mean & STD & & & \\
\hline$R_{\mathrm{a}}$ & 0.30 & 0.09 & 0.26 & 0.03 & 0.33 & 0.11 & 0.24 & 0.51 & 0.30 \\
\hline$R_{\mathrm{z}}$ & 2.31 & 0.54 & 2.06 & 0.31 & 2.41 & 0.64 & 1.76 & 2.41 & 2.24 \\
\hline$R_{\mathrm{pk}}$ & 0.28 & 0.03 & 0.20 & 0.07 & 0.27 & 0.04 & 0.15 & 0.62 & 0.23 \\
\hline
\end{tabular}

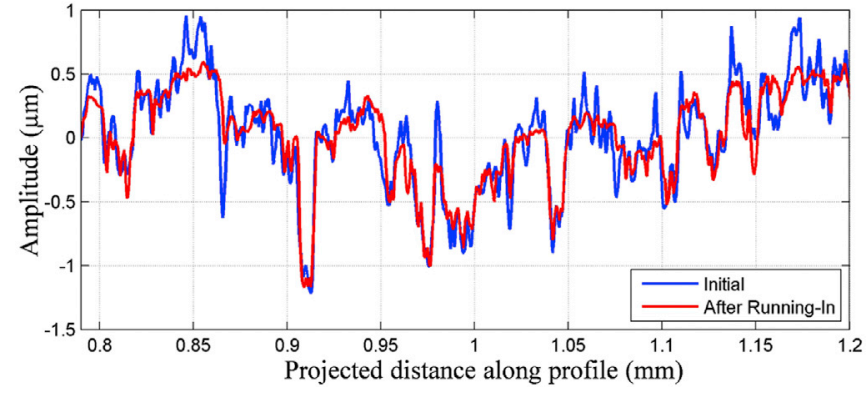

Fig. 10. Example of profile measurements comparing as-ground (initial) with after running-in.

seen for RI9+E. In the outermost part (less than a micron in depth), martensite plates in the deformed region were distorted in the sliding direction.

Short microcracks limited to the thickness of martensite plates were observed both on as-ground gear (Fig. 18, left) and for other test conditions.

Longer cracks were only observed for RI9+E near dedendum. Fig. 19 shows cross sections both in profile direction and in axial direction close to SAP. In the section cut in axial direction, multiple surface cracks that extend some $10-20 \mu \mathrm{m}$ into the material can be seen. This is the region where extensive micropitting was seen for the same condition as in Fig. 6.
The sliding shown in Fig. 17 is perpendicular to this cut and therefore not seen.

In sections cut in profile direction large cracks were observed to a depth of approximately $380 \mu \mathrm{m}$ with minimum length of $250 \mu \mathrm{m}$ (Fig. 19), still only for RI9+E near dedendum. Similar cracks were observed on some of the multiple sections of this kind from different teeth. Etching on these sections (not shown) revealed that some long cracks passed through martensite plates in the same manner as the short cracks (Fig. 18). Inclusions were also found along the cracks, see Fig. 20.

\subsection{Surface chemistry}

The surface analysis results will be presented as XPS depth profiles. For the tested gears no difference were found between tip, pitch and dedendum. Hence, results for the later were selected to represent the test conditions.

A depth profile for as-ground tooth are shown in Fig. 21a. The surface was rich in $\mathrm{C}, \mathrm{O}$ and $\mathrm{Fe}$ but the supposed Fe-oxide was limited to a few outermost nm for all conditions. Carbon was removed after the first etch cycle. This is typical for contamination, but it cannot be excluded that some $\mathrm{C}$ from the lubricant remain after cleaning of the sample. The alloying elements $\mathrm{Cr}$ and $\mathrm{Mn}$ were also detected. These elements are presented in the upper part of all Figs. 21-23. However, the focus here will be on other elements, in particular those from lubrication additives, presented in the lower part. The most characteristic elements for the asground tooth was S and Si. Still, N, Al, P, Ca, and F were also recorded in

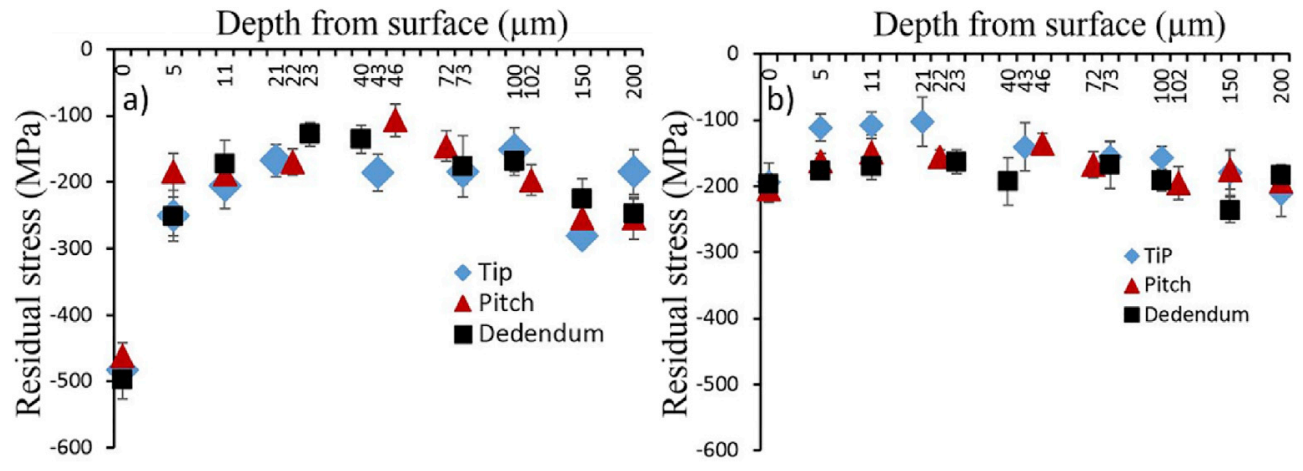

Fig. 11. Residual stress profiles of an as-ground tooth in a) profile and b) axial direction.

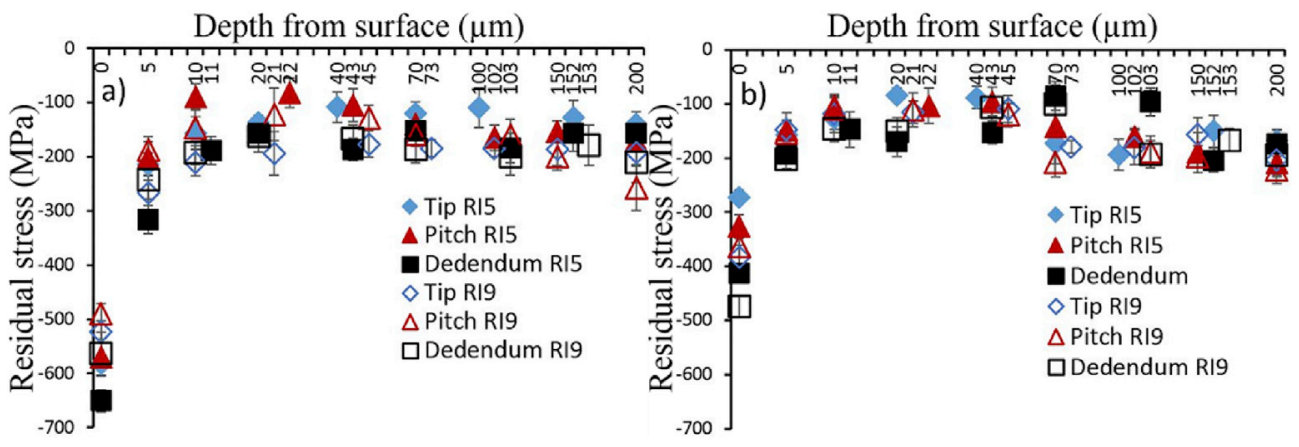

Fig. 12. Residual stress profiles after running-in in a) profile and b) axial direction. 

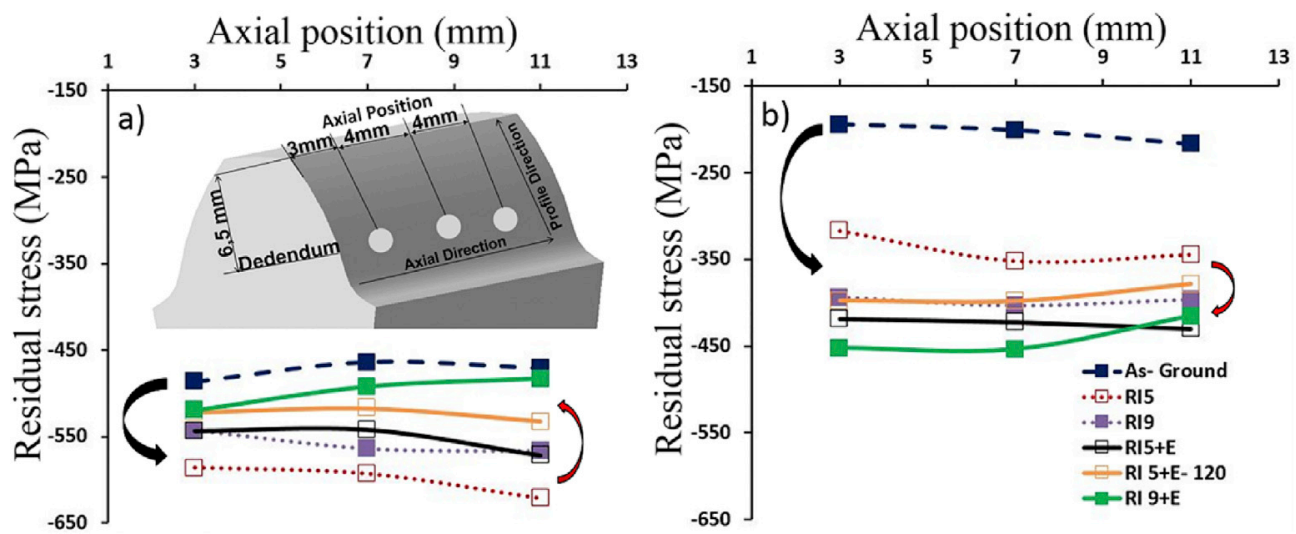

Fig. 13. Surface residual stresses for three points in axial position at dedendum for different test conditions in a) profile and b) axial direction.

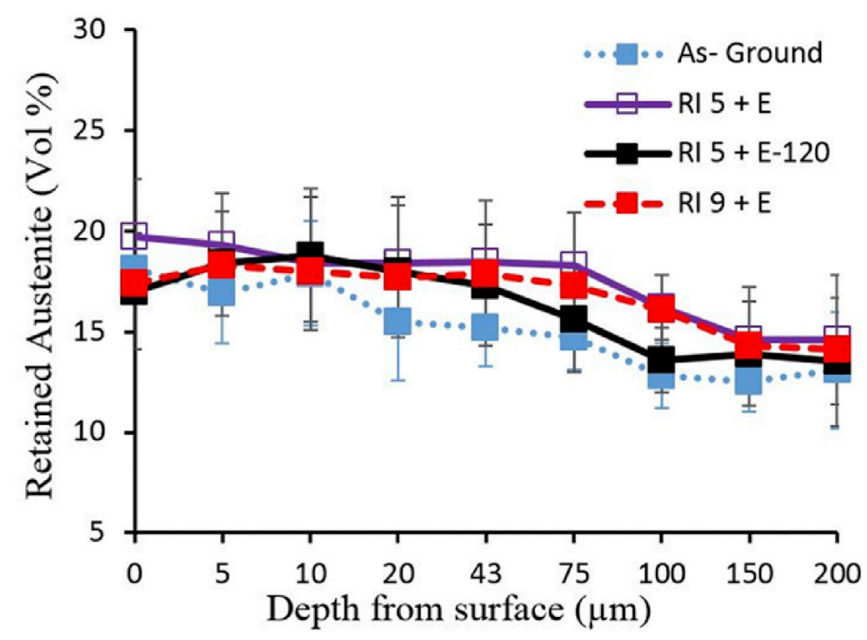

Fig. 14. Retained austenite profiles after efficiency tests compared to as-ground condition.

low amounts i.e. $\leq 1$ atomic percent. Sulphur, $\mathrm{Si}$ and $\mathrm{Al}$ were present down to about $5 \mathrm{~nm}$ below the original surface. Fig. 21b shows depth profiles after static immersion test (SIT). Again, the highest amounts in the lower profile were recorded for $\mathrm{S}$ and $\mathrm{Si}$, but the most significant difference compared to the as-ground tooth was the presence of $\mathrm{P}$ within the outermost $2 \mathrm{~nm}$. Furthermore, higher $\mathrm{N}$ content was observed at the surface. For the other elements, the profiles were similar to the asground condition.

More P from EP additive was observed after running-in, see Fig. 22.
The concentration and profile shape for P were similar for RI5 and RI9 with $>1$ atomic percent found down to approximately $10 \mathrm{~nm}$ below the original surface. Notably, less S was found after running-in than before but in similar amounts between running-in tests. The $\mathrm{N}$ profiles were similar between running-in tests and SIT. A distinctive feature to be observed between running-in tests is $\mathrm{Si}$, which follows $\mathrm{P}$ with similar amount for test condition RI5 but not for RI9.

The most interesting result from the surface analyses is possibly the $\mathrm{P}$ profiles after efficiency testing (Fig. 23). After RI9+E, P is present much deeper into the surface and at higher concentrations than for other conditions. In contrary, after RI5+E less $\mathrm{P}$ was present than even after RI5. Significant amounts of Ca were also recorded after RI9+E. Regarding $\mathrm{Si}$ a similar trend was found as after running-in; significant amounts after RI5+E and less after RI9+E. The profile for RI5+E-120 (not shown) was similar to that for RI5.

\section{Discussion}

Ideally, running in should smoothen the asperities and contribute to the formation of a tribofilm that both improve the efficiency at the same time as the process increases the compressive residual stresses that may enhance the fatigue life. The running-in processes studied here have smoothened the asperities through plastic deformation and increased the level of compressive residual stresses. However, the stress change was confined to a few microns and the process also initiated the formation of micropits. Only limited reactions with the EP additives in the lubricant occurred during the running in.

The smoothening of the asperities can consistently be seen from both the profilometer measurements and the SEM micrographs. The main advantage of the profilometry is the quantification of the results, and that it can be done in situ to follow a test. Detailed observation as in Fig. 10
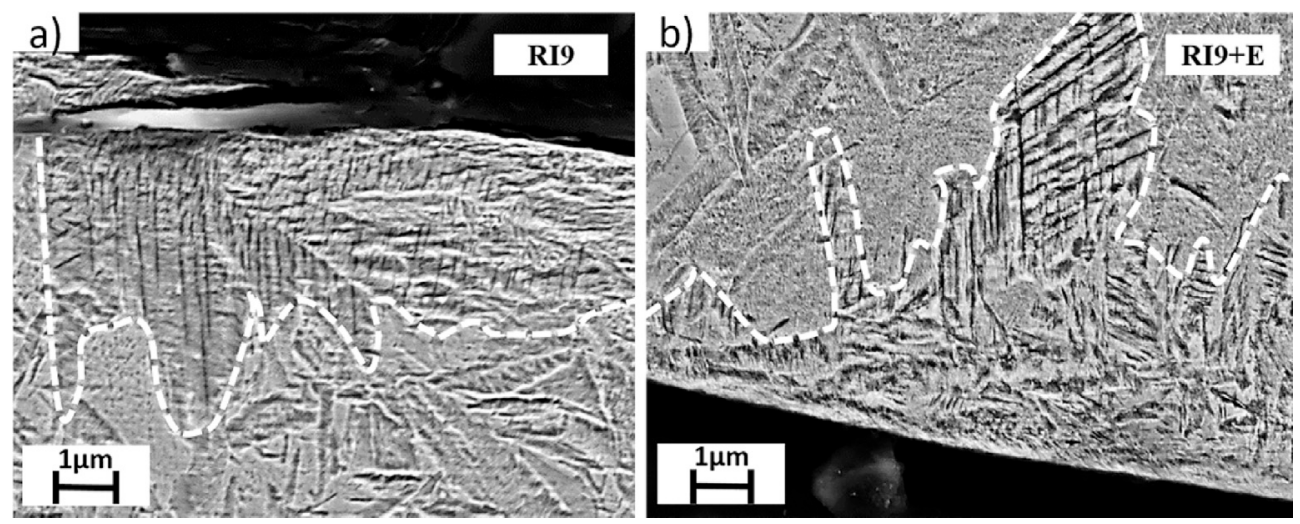

Fig. 15. Deformation induced martensite observed after a) RI9 and b) RI9+E test. 

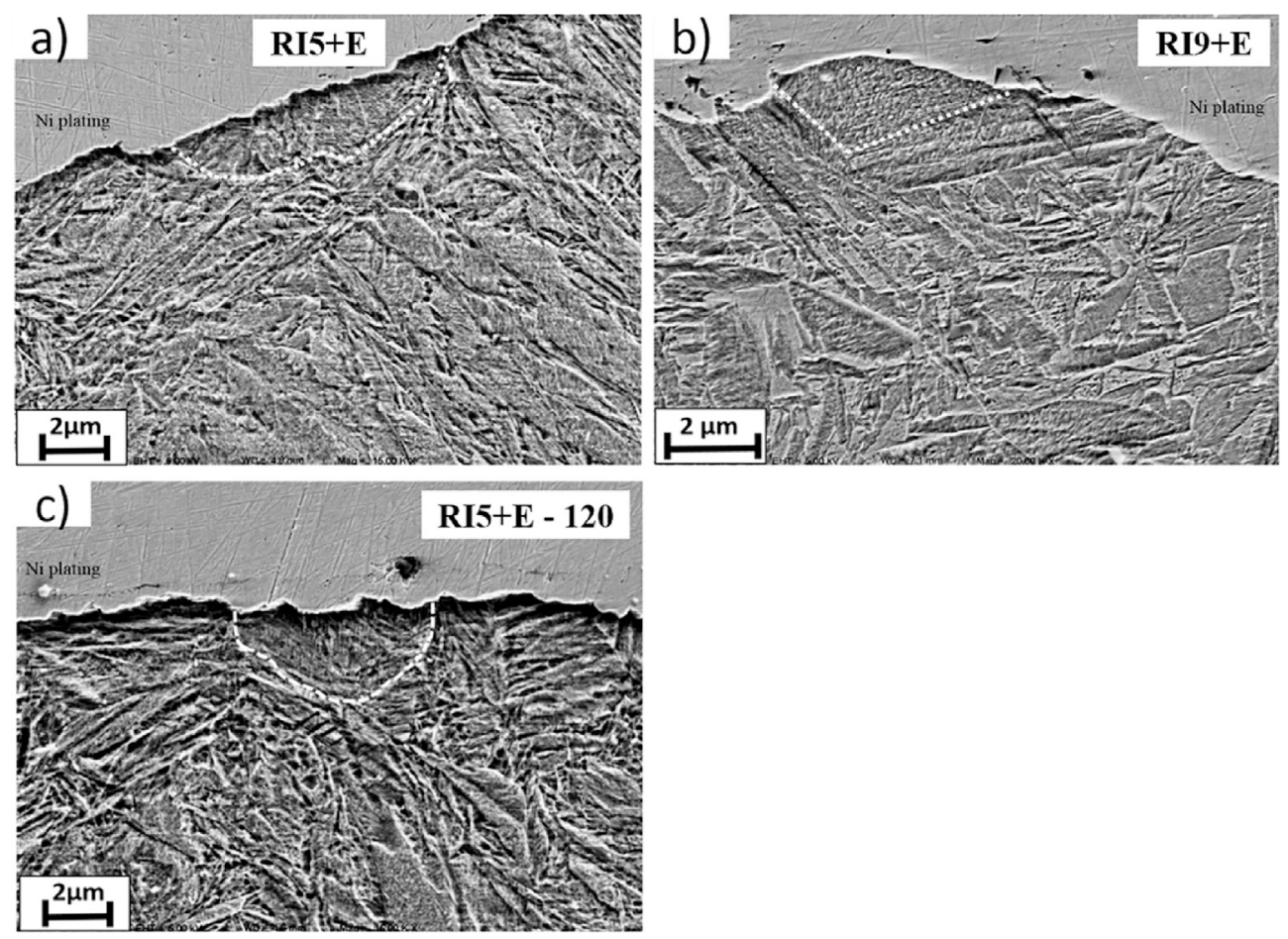

Fig. 16. SEM images with encircled plastic deformation regions at the surfaces for different test conditions a) RI5+E, b) RI9+E and c) RI5+E-120.
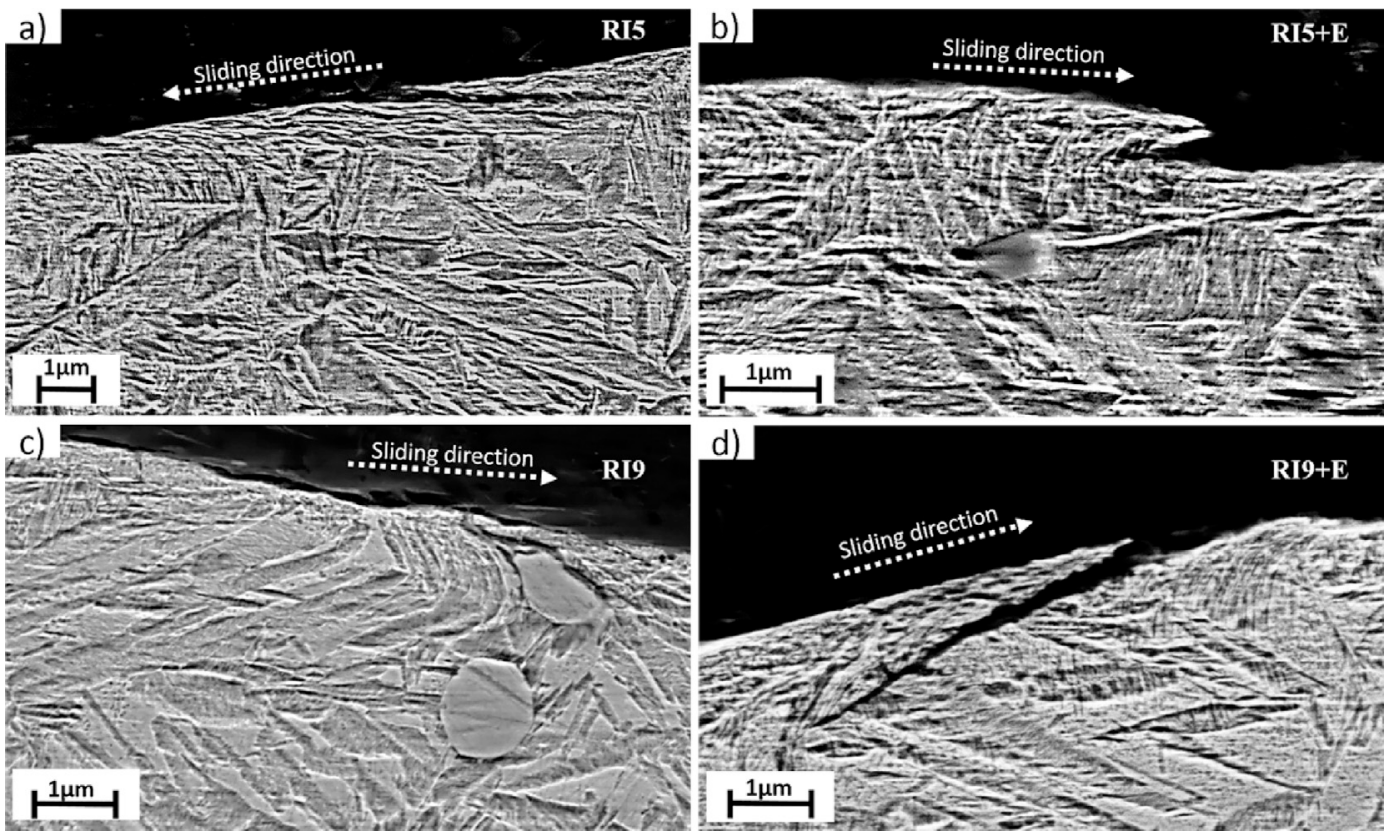

Fig. 17. Surface deformation at dedendum after a) RI5, b) RI5+E, c) RI9 and d) RI9+E test.

also give quantitative information about individual asperities. Still, the SEM is vital to understand the deformation that affects the gear surface. The plastic deformation of the asperities in the sliding direction during running-in can be seen both in top views (e.g. Figs. 6 and 8) and in cross sections (Fig. 17). As can be expected the deformation was more severe after RI9 than RI5 since higher load raises the contact stress at the asperity level. After efficiency testing, the asperities were further smoothened. Test condition RI5+E-120 gave the smoothest surface at both tip and dedendum compared to other efficiency tests. Even though there was a bit more P on RI5+E-120 than RI5+E it was far less than for $\mathrm{RI9+E}$. The established microstructures and residual stresses for RI5+E-
120 and RI5+E were rather similar. Altogether, it remains unknown why the efficiency test at $120^{\circ} \mathrm{C}$ gave a more even surface.

The plastic deformation has also affected the microstructure. The asground gears have a plate martensitic structure with about $20 \%$ retained austenite. For all test conditions except for RI5 deformation-induced martensite was considered to formed close $(<7 \mu \mathrm{m})$ to the surface and more so after the efficiency tests and in particular for RI9+E. Olson and Cohen [32] suggested that applied stress can induce martensitic transformation either by stress-assisted or by strain-induced mechanism. The reason for the absence of deformation-induced martensite in RI5 might be that the contact stresses did not provide the required driving force 

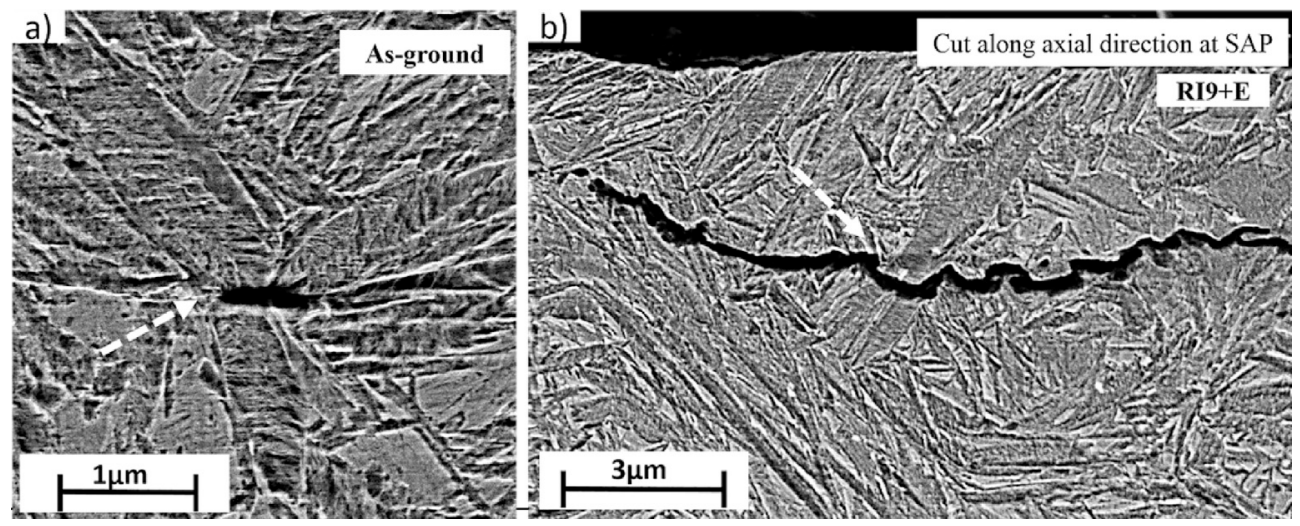

Fig. 18. Microcrack through a martensite plate a) as-ground condition and b) longer crack going through a martensite plate after RI9+E test.
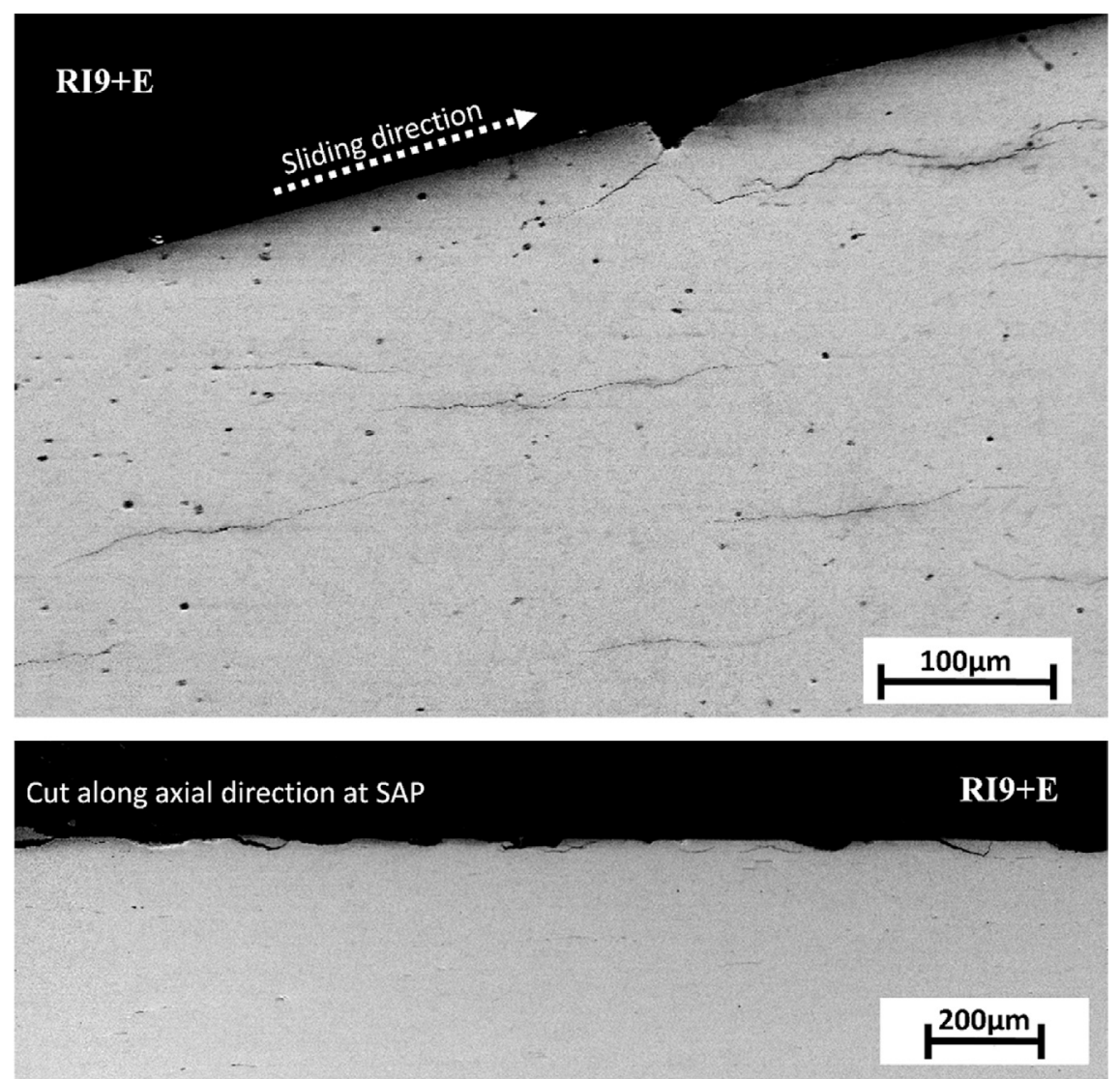

Fig. 19. Surface and subsurface cracks at dedendum after RI9+E test.

needed for the transformation. Shaw [31] studied the influence of retained austenite on the fatigue performance of case carburized gears. In that study, helical gear containing $60 \%$ retained austenite was tested with a contact stress of $1.455 \mathrm{GPa}$. After 32 million cycles of fatigue testing, $30 \%$ of the retained austenite was transformed to martensite. However, the transformation was limited to a shallow depth of around $10 \mu \mathrm{m}$. They also concluded that stress or strain induced martensitic transformation associated with $4 \%$ volume increase was a reason for increasing compressive residual stresses. Similarly, in the present study the transformation of retained austenite was also confined to shallow depth. The transformed percentage is so low that it is hard to determine statistically by using XRD. However, even a small fraction of transformation may contribute to increase the compressive residual stresses and the results show that a running-in cycle can be designed to achieve this.

In addition to deformation induced martensite, Fig. 16 depicts the formation of plastic deformation regions (PDR) at the surface. These regions were observed only for efficiency test conditions. In this study no dark etching regions have been noted at the edge of the PDR and no initiation of microcracks have been associated with them. Such a mechanism has been suggested by Oila [17] after testing with loads similar to RI9 but for higher number of cycles.

Apart from smoothening and structural changes, the plastic deformation also led to the formation of micropits already after running-in. Thus, initiation of micropits needed less than 20880 cycles. Micropits formed at dedendum for both RI9 and RI5 (to a lesser extent), but only for 

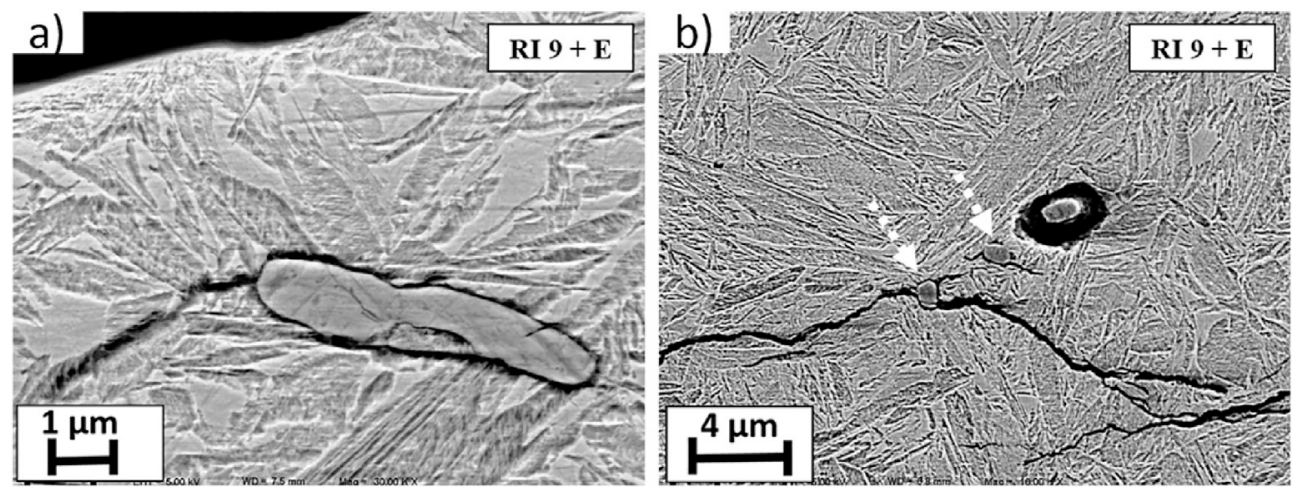

Fig. 20. Cracks connected to inclusions in RI9+E test a) short crack connected to inclusion b) both short and long cracks connected to two different close by inclusions.
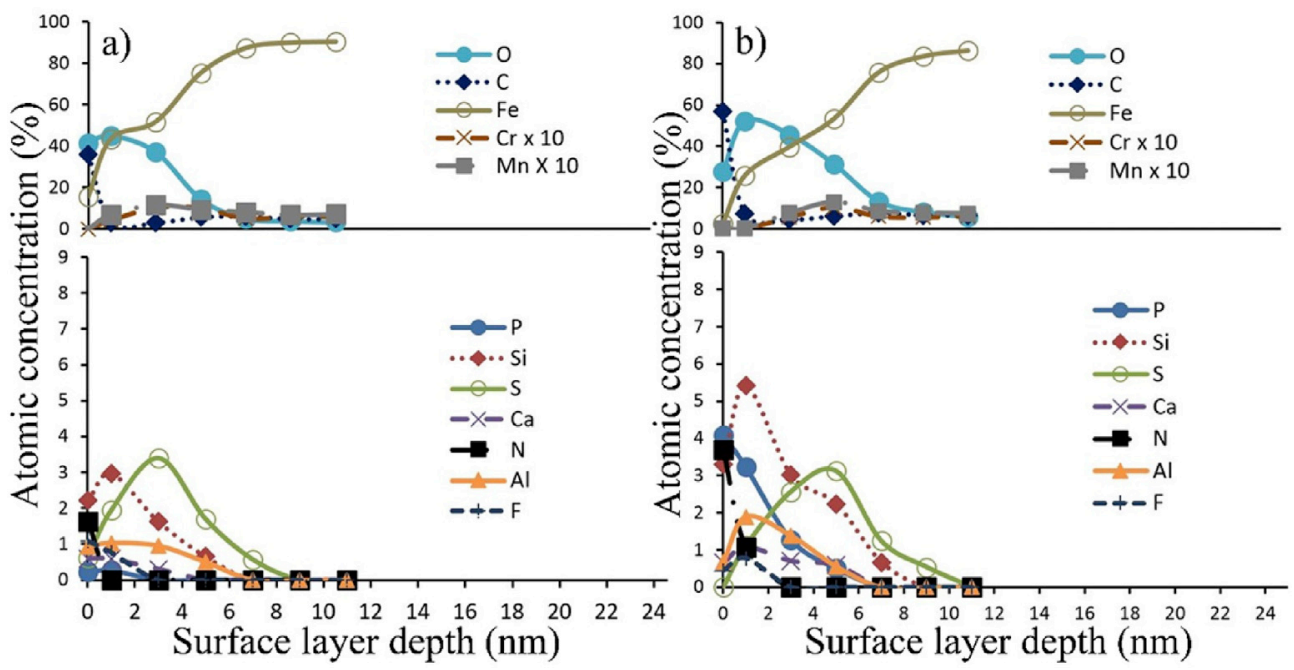

Fig. 21. XPS depth profiles of a) an as-ground tooth and b) after static immersion test.
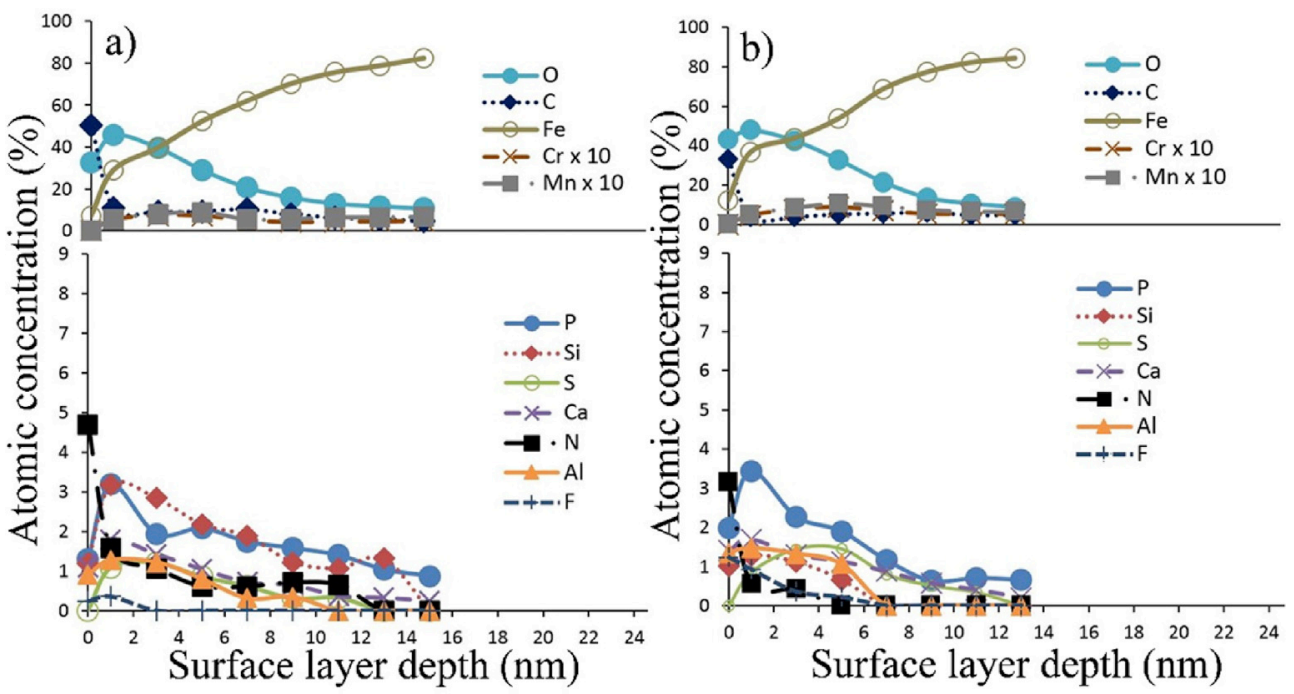

Fig. 22. XPS depth profiles after running-in a) RI5 b) RI9.

RI9 at the tip. This indicates the influence of running-in load on the initiation of micropits. Martins et al. [33] studied the evolution of roughness during micropitting tests and also observed micropitting after running-in. In that study, FZG-C type spur gears with high surface roughness of $1.45 \mu \mathrm{m} R_{a}$ were used instead of $0.3 \mu \mathrm{m} R_{a}$. The running-in parameters were $0.5 \mathrm{GPa}$ Hertzian pressure, $80{ }^{\circ} \mathrm{C}$ and $2250 \mathrm{rpm}$. Micropitting was observed after 135000 cycles, a substantially higher number than in the current study. However, this was based on low magnification images so it is reasonable to believe that the first micropits occurred at an earlier stage. Altogether, these studies are in reasonable 

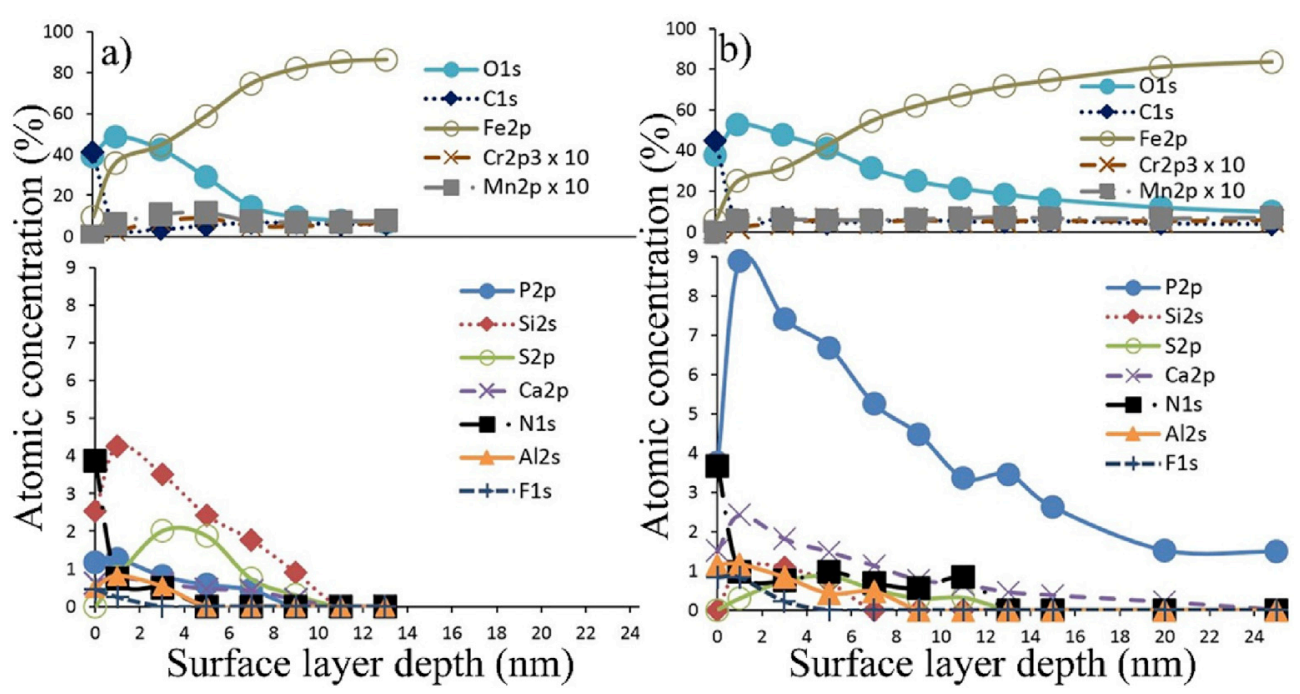

Fig. 23. XPS depth profiles after efficiency testing a) RI5+E b) RI9+E.

accordance. Both show that the amount of micropits increased with the load as seen here after efficiency testing. Thus, RI9+E has a higher amount of micropits than RI5+E. Another important observation is that the micropitting, as the asperity deformation, was more severe at dedendum compared to tip surfaces. The severe contact conditions due to negative sliding at dedendum [27], and the high load at the lowest point of single tooth contact [28] can be possible reasons for dedendum being more prone to micropitting.

The morphology of micropitting, see Fig. 7, confirms that the micropits are clearly related to the asperities and grow in the opposite direction to the sliding force [28]. Micro-Hertzian stress field below contacting asperities act as a primary stresses that initiate micropitting [18]. Both the normal force and sliding force acting on the asperity peak should contribute to the stresses below the asperity. In conjunction, the SEM cross section shown in Fig. 17 depicts the deformation of asperities in the direction of sliding. Such folded asperities will result in sharp angles where the stresses may be even more concentrated than with the original shape of the asperities, leading to crack initiation. Evans et al. [34] simulated surface fatigue damage of ground helical gears by coupling elastohydrodynamic lubrication contact analysis with plane strain fatigue and damage accumulation analysis. It showed that high pressures generated during contact are associated with a particular asperity and the distribution of pressure is narrow in width. In addition, the maximum intensity of stresses occurs at a shallow depth of that particular mating asperity. In simple words, the conclusion of the simulation work was that the micropitting in gears is mainly due to fatigue at the roughness asperity level.

The metallographic investigations revealed the presence of microcracks in martensite plates on as-ground gears. These cracks are expected to form during the heat treatment and martensite formation. When a secondary plate forms with another variant of habit plane in the same austenite grain, it can lead to cracking of the first at the contact between the plates [35]. This occurs mostly for large plates, just as seen in Fig. 18 with a crack through a larger plate at the contact with a smaller one. Only for RI9+E at dedendum longer sub surface cracks down to a depth of $380 \mu \mathrm{m}$ were observed. Some of these cracks also went through martensite plates in the same way as the microcracks. It is reasonable to believe that the microcracks have affected the growth of the subsurface cracks as well as the inclusions that were also associated with them.

The compressive residual stresses that are beneficial for the contact fatigue of gears can evolve differently depending on the loading conditions. Therefore, attention must be paid on the distribution and evolution of residual stresses in order to understand their influence on contact fatigue. Primarily, on the surface of as-ground gear teeth, a non-equal biaxial stress state was found with compressive stresses in profile direction more than twice those in axial direction. However, the depth profiles showed that from about $5 \mu \mathrm{m}$ beneath the surface there is no difference in stress levels between profile and axial direction. This confirms that deformation created by grinding process is confined only to the surface layer. A similar trend for surface stresses was observed in a round robin study [36] that included determination of residual stresses induced by hard finishing. The case stresses deeper in were about $300 \mathrm{MPa}$. After running-in, the compressive residual stresses increased in both profile and axial directions as compared to as-ground gear. Higher running-in load induced higher stresses in axial direction and lower stresses in profile direction. After efficiency testing the compressive residual stresses had increased further in axial direction and decreased in profile direction so the difference in stress levels between directions was reduced further. However, in line with the running-in tests the inequality in stress levels were lower for RI9+E compared to RI5+E. The trend to more equal stresses with increasing number of cycles, as after efficiency testing, has been reported for contact fatigue tested gears, but for higher loads and much higher number of cycles [36]. There, the axial stresses for ground gears increased while the profile stresses for honed gears decreased to a common interval of 450-600 MPa in both directions, irrespective of manufacturing process, after $10.5 \times 10^{6}$ cycles. The indepth residual stress profiles confirmed that change in stress levels during testing was limited to the surface. Similar results were reported by Batista et al. [20]. In that study, shaved helical gears, surface treated by carbo-nitriding were tested for contact fatigue. After $30 \mathrm{hrs}$ of testing, an increase in compressive residual stresses was observed but only at the surface i.e. down to $10 \mu \mathrm{m}$. Altogether, the running-in do contribute to the residual stresses and both the load and the number of cycles affect the results. However, as for other characteristics, the running-in is not an isolated process and the residual stress levels continue to evolve during usage of the gear.

Regarding the XPS depth profiles, it should be remembered that the analysis area was about $0.8 \mathrm{~mm}$ in diameter, there was some roughness on the samples and the surface films may not be homogeneous. The roughness gives higher contact pressures at the asperity peaks that promote the reaction between the EP additives in the lubricant and the metal surface. The ion etching will also be influenced by the roughness. The samples where oriented for maximal etch rate on the nominal surface profile, but in e.g. valleys in the grinding lay the angle of ion incidence can give slower etching and in e.g. deep pits shading may occur. Therefore, though the profiles show concentrations vs etch depth, they 
may be interpreted rather as indications of surface coverage, than concentrations in a homogeneous layer with uniform thickness.

All elements found were observed already in the as-ground condition. In particular, there was more $S$ before than after gear testing. Thus, it is supposed that the surface chemistry for the very initial running-in will be set by the grinding coolant and its additives rather than the transmission oil.

Then, the chemistry develops depending on the testing. The detailed composition of the oil and the additives used are not known and therefore it can be difficult to distinguish which elements that may be contaminants. Hence, the origin of $\mathrm{Al}$ and $\mathrm{F}$ present on all surfaces is not known, but they are not common contaminants in surface analysis. Silicon is often encountered as a contaminant in surface analysis, but here it is recorded to similar depths as $\mathrm{P}$, and it can be present in anti-foaming agents in the oil. Though the later are not intended to interact with the metal surfaces, it is assumed that the $\mathrm{Si}$ in the profiles is related to the lubricant. Still, further analyses would be required to explain the differences between conditions. Likewise, the observation of Ca should be related to its use in detergent additives.

The amount of $\mathrm{P}$ on the surfaces increased after the static immersion test, and further so after running-in to similar extent for both loads. However, the amounts remained low and limited to a layer of about $10 \mathrm{~nm}$. After efficiency testing RI5+E the amount of P was even lower. Instead, some $S$, present in the oil additives, was observed together with $\mathrm{Si}$ but the amounts remained limited. Only for RI9+E a substantial amount of $\mathrm{P}$ was present in concentrations up to 9 atomic- $\%$ and still noticeable after $20 \mathrm{~nm}$ etching. A significant tribofilm seems to have formed with the EP additives for this test condition.

Interestingly, when these gears were examined previously the highest running-in load gave the highest mesh efficiency as well as the smoothest surfaces in the following efficiency test [9]. Here, it was found that a tribofilm with significant amount of $\mathrm{P}$ was formed for the same condition, RI9+E. Furthermore, the surface topography trend was confirmed by SEM imaging. However, it was also found that both sub-surface cracks and more micropits were formed during the efficiency test that followed running-in at higher load.

\section{Conclusions}

In this study, the effect of load on the evolution of surface characteristics during running-in and initial usage (efficiency testing) was studied. The conclusions are as follows:

$>$ In general, the running-in and efficiency test influenced the surface characteristics to a layer limited to $<10 \mu \mathrm{m}$.

$>$ The surface asperities were smoothened through plastic deformation while micropitting occurred readily after running-in.

$>$ Higher running-in load gave more micropitting, also after identical efficiency tests.

$>$ Micropitting was associated with asperities. Folded asperities will result in sharp angles where the stresses may be even more concentrated than with the original shape of the asperities, leading to crack initiation.

$>$ No connection between micropitting and phase transformation was found.

$>$ Plastically deformed regions were observed down to $5 \mu \mathrm{m}$ after all the efficiency test conditions, but no cracks were associated with these regions.

$>$ For all the tested gears, the evolution of residual stresses was confined to the surface layer of about $5 \mu \mathrm{m}$. Running-in increased the surface stresses in both profile and axial direction. After efficiency testing the difference in stress levels between directions was further reduced to approach similar levels.

$>$ Deformation induced martensite was formed during running-in only at high load. The amount formed after efficiency testing increased with running-in load. The transformation was confined to a surface layer $<7 \mu \mathrm{m}$.

$>$ The formation of tribofilms was limited after running-in. Higher amount of P, supposedly from EP additive, was only observed for the efficiency test condition that was run at higher running-in load.

\section{Acknowledgements}

This work was done in cooperation with $\mathrm{AB}$ Volvo and Scania CV $\mathrm{AB}$. The authors would like to thank prof. U. Olofsson at the Royal Institute of Technology for valuable discussions and support. The Swedish Energy Agency (2011-005448) and the Swedish Agency for Innovation Systems (2015-06908) (VINNOVA) are acknowledged for financial support.

\section{References}

[1] Holmberg K, Andersson P, Nylund N-O, Mäkelä K, Erdemir A. Global energy consumption due to friction in trucks and buses. Tribol Int 2014;78:94-114. http:// dx.doi.org/10.1016/j.triboint.2014.05.004.

[2] Andersson M, Sosa M, Olofsson U. The effect of running-in on the efficiency of superfinished gears. Tribol Int 2016;93:71-7. http://dx.doi.org/10.1016/ j.triboint.2015.08.010.

[3] Petry-Johnson TT, Kahraman a, Anderson NE, Chase DR. An experimental investigation of spur gear efficiency. J Mech Des 2008;130:62601. http:// dx.doi.org/10.1115/1.2898876.

[4] Britton RD, Elcoate CD, Alanou MP, Evans HP, Snidle RW. Effect of surface finish on gear tooth friction. J Tribol 2000;122:354. http://dx.doi.org/10.1115/1.555367.

[5] Andersson S. Initial wear of gears. Tribol Int 1977;10:206-10. http://dx.doi.org/ 10.1016/0301-679X(77)90021-4.

[6] Ismail R, Tauviqirrahman M, Schipper DJ. Topographical change of engineering surface due to running-in of rolling contacts. 1998.

[7] Hsu SM, Munro RG, Shen MC, Gates RS. Boundary lubricated wear. In: Wear Mater. Mech. Pract. Chichester, England: John Wiley \& Sons Ltd; 2014. p. 37-70. http://dx.doi.org/10.1002/9780470017029.ch4.

[8] Kragelsky IV, Dobychin MN, Kombalov VS. Running-in and equilibrium roughness. Frict Wear 1982:297-316. http://dx.doi.org/10.1016/B978-0-08-025461-6.500147.

[9] Sjöberg S, Sosa M, Andersson M, Olofsson U. Analysis of efficiency of spur ground gears and the influence of running-in. Tribol Int 2016;93:172-81. http:// dx.doi.org/10.1016/j.triboint.2015.08.045.

[10] Cavatorta MP, Cusano C. Running-in of aluminum/steel contacts under starved lubrication Part I. Effects on scuffing. Wear 2000;242:133-9. http://dx.doi.org/ 10.1016/S0043-1648(00)00412-9.

[11] Alban LE. In: Failures of gears, vol. 11. ASM Int; 1986. p. 586-601.

[12] Ariura Y, Ueno T, Nakanishi T. An investigation of surface failure of surfacehardened gears by scanning electron microscopy observations. Wear 1983;87: 305-16. http://dx.doi.org/10.1016/0043-1648(83)90134-5.

[13] Brechot P, Cardis AB, Murphy WR, Theissen J. Micropitting resistant industrial gear oils with balanced performance. Ind Lubr Tribol 2000;52:125-36. http:// dx.doi.org/10.1108/00368790010371762.

[14] Höhn BR, Oster P, Emmert S. Micropitting in case-carburized gears - FZG micropitting test. In: Int. Conf. Gears, Dresden; 1996. p. 331-4.

[15] Oila A, Bull SJ. Assessment of the factors influencing micropitting in rolling/sliding contacts. Wear 2005;258:1510-24. http://dx.doi.org/10.1016/ j.wear.2004.10.012.

[16] Oila A, Bull SJ. Phase transformations associated with micropitting in rolling/ sliding contacts. J Mater. Sci 2005;40:4767-74. http://dx.doi.org/10.1007/ s10853-005-2017-5.

[17] Oila A, Shaw BA, Aylott CJ, Bull SJ. Martensite decay in micropitted gears. Proc Inst Mech Eng Part J J Eng Tribol 2005;219:77-83. http://dx.doi.org/10.1243/ $135065005 X 9790$.

[18] Hoeprich MR. Analysis of micropitting of prototype surface fatigue test gears. Tribotest 2001;7:333-47. http://dx.doi.org/10.1002/tt.3020070406.

[19] Bush JJ, Grube WL, Robinson GH. Microstructural and residual stress changes in hardened steel due to rolling contact. Trans ASM 1961;54:390-412.

[20] Batista A, Dias A, Lebrun J, Le Flour C, Inglebert G. Contact fatigue of automotive gears: evolution and effects of residual stresses induced by surface treatments. Fatigue Fract Eng Mater. Struct 2000;23:217-28.

[21] Krantz TL. On the correlation of specific film thickness and gear pitting life. Gear Technol 2015:52-62.

[22] Stratmann A, Hentschke C, Jacobs G. Formation of anti-wear films in rolling bearings due to run-in procedures. In: Proc. World Tribol. Congr; 2013. p. 1-4.

[23] Michaelis K, Höhn BR, Doleschel A. Method to determine the frictional behaviour of lubricants using a FZG gear test rig, Frankfut FVA Tech. Rep. 345. 2002.

[24] FVA-Group. Research project No.345 efficiecny test. FVA Frankfut. 2002.

[25] Sosa M, Björklund S, Sellgren U, Olofsson U. In situ surface characterization of running-in of involute gears. Wear 2014;340-341:41-6. http://dx.doi.org/ 10.1016/j.wear.2015.03.008.

[26] Fitzpatrick ME, Fry AT, Holdway P, Kandil FA, Shackleton J, Suominen L. Determination of residual stresses by X-ray diffraction-issue 2. 2005. 
[27] Fernandes PJL, McDuling C. Surface contact fatigue failures in gears. Eng Fail Anal 1997;4:99-107. http://dx.doi.org/10.1016/S1350-6307(97)00006-X.

[28] Errichello R. Morphology of micropitting. Gear Technol 2012:74-81.

[29] Mallipeddi D, Norell M, Sosa M, Nyborg L. Stress distribution over gear teeth after grinding, running-in and efficiecny testing. In: Int. Conf. Gears VDI-Berichte, 2255.2; 2015. p. 973-84.

[30] Das A, Sivaprasad S, Chakraborti PC, Tarafder S. Morphologies and characteristics of deformation induced martensite during low cycle fatigue behaviour of austenitic stainless steel. Mater. Sci Eng A 2011;528:7909-14. http://dx.doi.org/10.1016/ j.msea.2011.07.011.

[31] Shaw BA, Abudaia FB, Evans JT. Characterization of retained austenite in case carburized gears and its influence on fatigue performance. Gear Technol 2003 : $12-6$.
[32] Olson GB, Feinberg ZD. Kinetics of martensite transformations in steels. Phase Transform Steels 2012;2:59-82. http://dx.doi.org/10.1016/B978-1-84569-9710.50003-X.

[33] Locateli C, Martins R, Seabra J. Evolution of tooth flank roughness during gear micropitting tests. Ind Lubr Tribol 2011;63:211-2. http://dx.doi.org/10.1108/ 00368791111101821.

[34] Evans HP, Snidle RW, Sharif KJ, Shaw BA, Zhang J. Analysis of microelastohydrodynamic lubrication and prediction of surface fatigue damage in micropitting tests on helical gears. J Tribol 2012;135:11501. http://dx.doi.org/ 10.1115/1.4007693.

[35] Krauss G. Steels - processing, structure, and performance. ASM International; 2005.

[36] Vasilio V, Gorgelsad C, Fritz K. Influence of the residual stresses induced by hard finishing processes on the running behaviour of gears. AGMA 09FTM01. 2009. 